\title{
The Charisma of Coastal Ecosystems: Addressing the Imbalance
}

\author{
Carlos M. Duarte • William C. Dennison • \\ Robert J. W. Orth • Tim J. B. Carruthers
}

Received: 5 October 2007 /Revised: 11 December 2007 / Accepted: 22 January 2008 / Published online: 15 February 2008

(C) Coastal and Estuarine Research Federation 2008

\begin{abstract}
Coastal ecosystems including coral reefs, mangrove forests, seagrass meadows, and salt marshes are being lost at alarming rates, and increased scientific understanding of causes has failed to stem these losses. Coastal habitats receive contrasting research effort, with $60 \%$ of all of the published research carried out on coral reefs, compared to $11-14 \%$ of the records for each of salt marshes, mangrove forests, and seagrass meadows. In addition, these highly connected and interdependent coastal ecosystems receive widely contrasting media attention that is disproportional to their scientific attention. Seagrass ecosystems receive the least attention in the media $(1.3 \%$ of the media reports) with greater attention on salt marshes $(6.5 \%)$, considerably more attention on mangroves $(20 \%)$, and a dominant focus on coral reefs, which are the subject of three in every four media reports on coastal ecosystems $(72.5 \%)$. There are approximately tenfold lower reports on seagrass meadows in the media for every scientific paper published (ten), than the 130-150 media reports per scientific paper for mangroves and coral reefs. The lack of public awareness of losses of less charismatic ecosystems
\end{abstract}

\footnotetext{
C. M. Duarte $(\square)$

Instituto Mediterráneo de Estudios Avanzados, CSIC-UIB,

Miquel Marqués 21,

07190 Esporles (Mallorca), Spain

e-mail: carlosduarte@ifisc.uib.es

W. C. Dennison · T. J. B. Carruthers

University of Maryland Center for Environmental Science,

Cambridge, MD 21613, USA

R. J. W. Orth

School of Marine Science, Virginia Institute of Marine Science,

College of William and Mary,

Gloucester Point, VA 23062, USA
}

results in the continuation of detrimental practices and therefore contributes to continued declines of coastal ecosystems. More effective communication of scientific knowledge about these uncharismatic but ecologically important coastal habitats is required. Effective use of formal (e.g., school curricula, media) and informal (e.g., web) education avenues and an effective partnership between scientists and media communicators are essential to raise public awareness of issues, concerns, and solutions within coastal ecosystems. Only increased public understanding can ultimately inform and motivate effective management of these ecologically important coastal ecosystems.

Keywords Seagrass $\cdot$ Coastal habitats $\cdot$ Charisma $\cdot$ Media . Decline $\cdot$ Conservation

\section{Introduction}

Increased human population and associated pressures on the environment are leading to worldwide declines of key ecosystems, eroding biological diversity and ecosystem functions (e.g., Balmford and Bond 2005). This is particularly apparent in the coastal zone, defined as plus or minus $200 \mathrm{~m}$ elevation from current sea level, which constitutes twenty per cent of the earth's surface (Pernetta and Milliman 1995) and is home to much of the global human population; $37 \%$ being within just $100 \mathrm{~km}$ of the coastline (NRC 1990; Cohen et al. 1997). This proportion is growing a large block of text as a result of population growth and migration to these regions (Curran et al. 2002), with the result that seventy per cent of the world's megacities $(>1.6$ million) are now in the coastal zone (LOICZ 2002). These increasing anthropogenic pressures have led to a sustained global loss of coral reefs, mangrove forests, salt marshes, 
Fig. 1 Areal extent, published loss rates, and estimated ecosystem value for key global ecosystems in both tropical and temperate regions

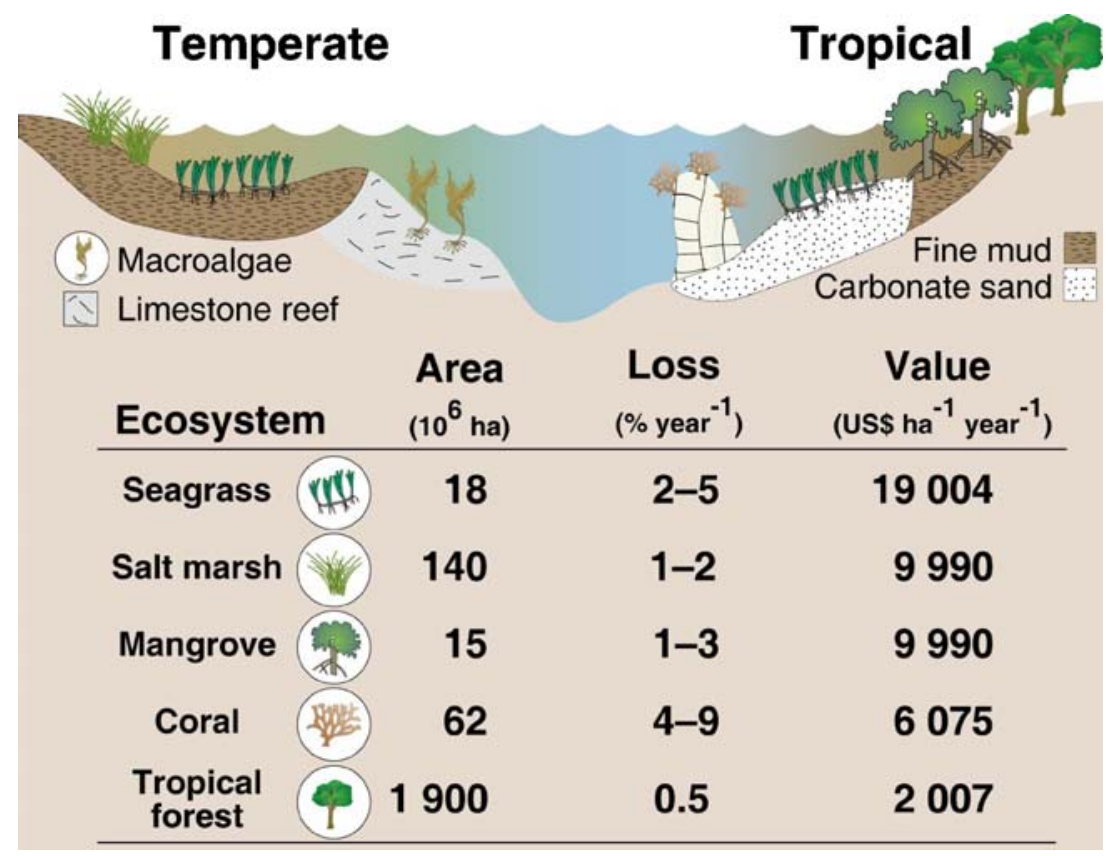

and seagrass meadows over the past five decades (Fig. 1). The mechanisms of these losses are multiple, including land reclamation, coastal development, excess sediment, nutrient and organic inputs, overfishing, mechanical damage by boats and fishing gear, logging, and impacts from invasive species and intensive aquaculture and susceptibility to climate change (e.g., Ellison and Stoddart 1991; Jackson et al. 2001; Adam 2002; Duarte 2002; Bellwood et al. 2004; Lotze et al. 2006; Orth et al. 2006).

Public awareness of these losses, as well as understanding of the processes and causes of loss, is necessary to motivate effective management and protect or restore these ecosystems. Even though these ecosystems are highly connected (Fig. 1), the information presented has been proportionately lacking for some coastal ecosystems such as seagrasses and salt marshes. Coastal ecosystems cannot be preserved in isolation from the adjoining ecosystems; therefore, a common public communication approach is required, presenting threats and issues related to all ecosystems in the coastal zone.

Losses of coastal habitats remain large even for the habitats, such as coral reefs, for which public awareness is highest, a fact that may discourage further actions. It is indeed important to recognize that local action alone does not suffice to revert all losses, since some impacts derive from global pressures (e.g., climate change), which cannot be controlled through local management actions alone. However, we argue that effective local management actions can help maintain and even expand the resistance and resilience of these systems to global pressures, so that, without this awareness, losses would likely be even higher.

\section{Valuable Coastal Ecosystems are in Decline}

The global loss rate of threatened coastal ecosystems is estimated at $4-9 \%$ year $^{-1}$ for corals (Gardner et al. 2003, Bellwood et al. 2004), a minimum of $1-2 \%$ year $^{-1}$ for saltmarshes (Adam 2002; Lotze et al. 2006), 1-3\% year ${ }^{-1}$ for mangroves (Valiela et al. 2001) and 2-5\% year ${ }^{-1}$ for seagrass meadows (Short and Wyllie-Echeverria 1998, Duarte 2002; Marbà et al. 2005; Orth et al. 2006; Fig. 1), all of which are more rapid than the global loss rate of tropical forests, estimated at $0.5 \%$ year $^{-1}$ (Achard et al. 2002). If these loss rates continue for yet another five decades, the amount of remaining coastal ecosystems would be reduced to less than $15 \%$ of the area present at the end of World War II. Impacts of these losses will be far reaching, not only continuing to erode biodiversity but reducing the provision of valuable ecosystem functions associated with these coastal ecosystems. Coral reefs, mangrove forests, salt marshes, and seagrass meadows have been estimated to deliver the highest annual value, in terms of ecosystem services [US \$6,000-19,000 ha ${ }^{-1}(1997$ value)] of all natural ecosystems on the planet (Fig. 1; Costanza et al. 1997). In comparison, tropical forests were estimated to supply US $\$ 2,000 \mathrm{ha}^{-1}$ (1997value; Fig. 1; Costanza et al. 1997). One practical and dramatic service provided by coastal ecosystems is to deliver protection to coastal communities from natural disasters (Adger et al. 2005). This was dramatically shown in December, 2004 when a large tsunami hit Southeast Asia, and a higher death toll occurred in villages devoid of mangrove protection than in those with preserved pockets of mangroves (Kathiresan 
and Rajendran 2005). It is also now recognized that damages from hurricane Katrina (August 2005) were exacerbated by the extensive loss of salt marshes in the Mississippi River delta (Tibbetts 2006). One response to these occurrences has been an effort to increase understanding of these processes.

\section{The Imbalance in Research Effort}

Scientific research has increased in response to these environmental challenges, with the annual rate of publication on coral reefs, mangrove forests, salt marshes, and seagrass meadows increasing by about twofold over the past 10 years (Orth et al. 2006), a similar rate of increase to that of research on tropical forests over the same period (twofold; Web of Science ${ }^{\mathrm{TM}}$ ). As a result, the Web of Science ${ }^{\mathrm{TM}}$ now lists about 30,000 scientific publications on these coastal ecosystems, which represents an important body of knowledge, but still only comprises one third of the research effort on tropical forests (about 100,000 publications). Within coastal ecosystems, approximately $60 \%$ of all of the published research has been carried out on coral reefs, compared to $11-14 \%$ of the records for each of salt marshes, mangrove forests, and seagrass meadows (Fig. 2a). This imbalance does not reflect the areal extent or the potential economic value of ecosystem services provided by different coastal ecosystems (Fig. 1) but more closely reflects the relative awareness of issues affecting these habitats.

\section{The Imbalance in Public Awareness}

To investigate the public awareness on coastal habitats, a survey of a range of international media outlets was carried out: National Geographic, USA (www.nationalgeographic. com); the New York Times, USA (www.nytimes.com); The Economist, UK (www.economist.com); the Internacional Herald Tribune (www.iht.com); the English version of the People Daily, China (www.english.peopledaily.com.cn); the English and Spanish versions of Google ${ }^{\mathrm{TM}}$ news (www. news.google.com/); El País, Spain (www.elpais.es); El Universal, Mexico (www.eluniversal.com.mx); the Discovery Channel, USA (www.dsc.discovery.com/); CNN, USA (www.edition.cnn.com); Le Monde, France (www.lemonde. fr); and Journal do Brasil (jbonline.terra.com.br). The electronic archives of these media outlets were searched between February and March, 2006, for reports on seagrass meadows, salt-marshes, mangrove forests, and coral reefs contained within their electronic archives. These electronic archives did not encompass the same period for all media outlets, precluding the consistent evaluation of the time

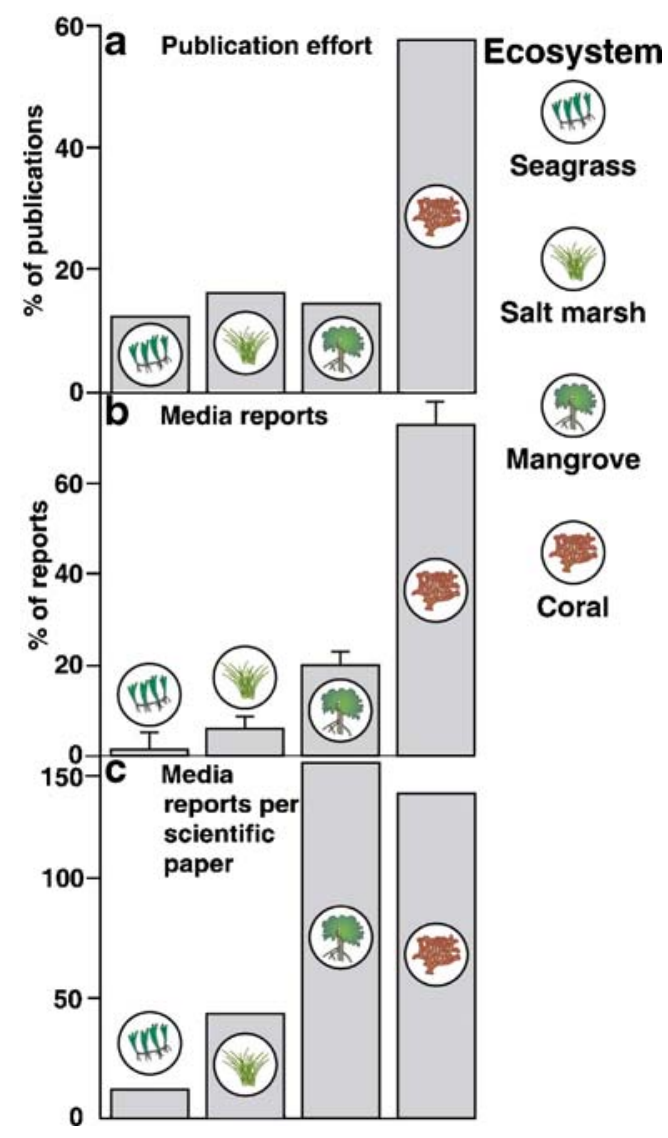

Fig. 2 a Publication effort (as \% of the total number of papers on threatened coastal habitats reported in Web of Science ${ }^{\mathrm{TM}}$ as of May 2006); b media reports (as the median of the percent of the reports across the 13 international sources searched); $\mathbf{c}$ and the media reports relative to scientific effort (as the ratio of the percent media reports in b and percent scientific effort in a; $100 \%$ represents a similar share of media reports and scientific efforts, $<100 \%$ represents a lower presence in the media as that in the scientific literature, and $>100 \%$ represents an excess presence in the media relative to that in the scientific literature). The error bars in b represent \pm 1 SE across the 13 sources examined

course of news reports on the different ecosystems. The adequacy of the reports was verified individually whenever the number of reports was $<500$ and corrected proportionately to the results of the verification of a random subset of 400 records for larger returns. A news item was considered adequate whenever it did not only include the key word but reported on some relevant element (status, functioning, management, science news, etc.) of the ecosystem of interest. The median percentage of reports received by any one ecosystem was calculated combining the calculated percentages for all 13 media sources.

We agree that the relationship between public awareness and newspaper reports may not be a simple one, as it involves feed backs: public awareness triggers interest and leads to newspaper reports, whereas more news reports lead 
to increasing awareness. We use news articles as a proxy for the level of awareness while avoiding discussing the causal link between these two aspects of society. To ascertain public awareness independently would require a broad questionnaire that will be possible, without huge resources, only at local scales, rendering the global scale addressed here impossible. The competition for space in top national journals is often as tough, or tougher, to provide a comparison, as that in Nature and Science. Hence, the perceived interest to the public is a prime component of the allocation of newspaper space to different items, so that more news items are assumed to correlate with greater awareness. As in our own research field, correlation cannot, however, be equated with causation.

The survey revealed public awareness to differ greatly across threatened coastal ecosystems (Fig. 2b), indicating that seagrass ecosystems receive the least attention in the media (1.3\% of the media reports) with greater attention on salt marshes $(6.5 \%)$, considerably more attention on mangroves $(20 \%)$, and a dominant focus on coral reefs, which are the subject of three in every four media reports on coastal ecosystems (72.5\%; Fig. 2b). These ratios are similar to those delivered by Google ${ }^{\mathrm{TM}}$, which returned, in May 2006, 1.6 million items on seagrasses compared to 80.6 million on coral reefs. Since research effort is not evenly allocated among threatened coastal ecosystems, it is hardly surprising that public perceptions are also imbalanced. Yet, public perceptions are far more skewed toward coral reefs than scientific efforts. Indeed, there are approximately tenfold lower reports on seagrass meadows in the media for every scientific paper published (ten) than the 130-150 media reports per scientific paper for mangroves and coral reefs (Fig 2c). These ratios are relative rather than absolute values, as the media search did not encompass all media produced globally, but they are, nevertheless, indicative of the apportioning of media attention relative to scientific effort. The impact of salt marsh scientific research on their visibility in the media has an intermediate position, with approximately 45 media reports per scientific paper published (Fig 1c). This contrast clearly indicates that research efforts on seagrass ecosystems have been particularly ineffective in raising public awareness compared to research on other coastal ecosystems, particularly coral reefs and mangrove forests. The relatively high awareness of mangrove forests may derive from a general concern on tropical forests rather than an interest in mangrove forest themselves, which are often poorly appreciated even by residents of mangrove areas.

Scientific efforts and public awareness are not independent, since public awareness of acute environmental problems, such as threats to the conservation of endangered coastal ecosystems, strongly affects patterns of resource allocation by public funding agencies. Research efforts and public awareness interact on a feed-back loop that helps address problems in charismatic ecosystems or species but may leave other similarly important issues behind in less appealing ecosystems. The results presented conclusively show seagrass meadows to be, in contrast to charismatic coral reefs, the 'ugly duckling' of coastal ecosystem conservation. The Merriam-Webster dictionary defined charisma as "a special magnetic charm or appeal" (www. merriam-webster.com). The results presented show coral reefs to be appealing to the media and the public that consume it and portray other ecosystems, such as seagrass meadows, as comparably uninteresting. We interpret this contrast to suggest that seagrass meadows are not, at present, charismatic to the public. The apparent lack of charisma of seagrass meadows is to some extent the result of their submersed growth, which hides them to the casual observer, and their resemblance to grasslands on land, which hardly raise public interest. In contrast, the dense array of dazzling and colorful fish and invertebrates that populate coral reefs fascinate the public, as indicated by the important tourism revenues supported by coral reefs. Coral reefs are popular subjects for nature documentaries and have been further popularized by top-hit films (e.g., Finding Nemo by Pixar Animation Studio, 2003).

\section{The Unobtrusive Charisma of Seagrass Ecosystems}

Seagrass meadows do host large organisms that could also attract the general public, such as tiger sharks, manatees, dugongs, turtles, seahorses, and giant bivalves (e.g., the Mediterranean Pinna nobilis). These are mostly endangered species and occur in far less numbers today than in the past due to overharvesting and habitat destruction (Jackson et al. 2001). The comparative lack of charisma of seagrass meadows to the public contrasts with the perception of scientists that these habitats rank among the most valuable ecosystems in the biosphere (Fig. 1; Costanza et al. 1997), which indicates that there is potential to raise the public knowledge of, and interest in, seagrass meadows. Indeed, the disproportionate media attention to corals relative to seagrass meadows is not a universal phenomenon, as seagrass meadows receive more attention than coral reefs in the French newspaper examined (Le Monde, $54.2 \%$ vs. $14.7 \%$ of reports on coastal habitats, respectively). This exception shows that the media, and the public, can become interested in seagrass meadows if, as in France, efforts are made to communicate the values of these ecosystems. Indeed, we envisage a positive feed-back loop, as exemplified by coral reefs, between increased information to the public and further demand for more information, which scientists may be able to catalyze. 


\section{Effective Communication is Essential}

Scientific understanding on the causes and consequences of ecosystem loss will be most effective in reversing the negative trajectories of coastal ecosystems if the science is converted to public awareness, which is essential to ensure ecosystem conservation (Inglehart 1995). However, scientific materials, typically as research papers, are not suitable for this goal. Increasing public awareness needs an overall strategy providing synthesis, visualization, and context, mediated through graphic rich materials which are contentrich and jargon-free (Thomas et al. 2006). One tool that can be a focus for this communication is the use of conceptual diagrams to synthesize key ecosystem features, functions, and threats (Dennison et al. 2007). Specifically, a successful strategy might include: (a) creating interest in these ecosystems, (b) providing pertinent information about their status and ecological role, and (c) encouraging involvement of citizens, governments, and non-government organizations in preserving and restoring coastal ecosystems. The elements of this strategy are mutually supportive, as information on the status and role of coastal ecosystems will help create interest and engage citizens and organizations in their conservations.

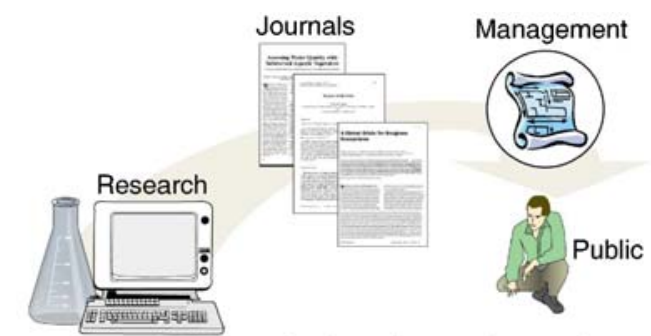

Conventional: Knowledge based products

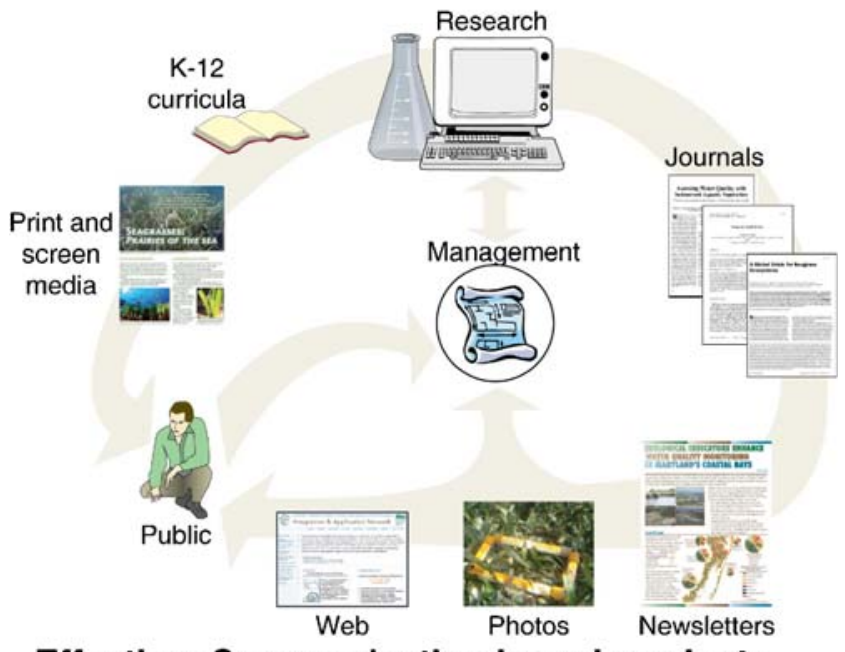

Effective: Communication based products

Fig. 3 Strategic diagram showing conventional and effective strategies for knowledge dissemination to address the challenges facing uncharismatic coastal ecosystems
A suite of high-profile scientific papers needs to be generated, accompanied with (Fig. 3) media releases and supplementary materials (web-based fact sheets, photos, databases, references) to maximize the broader impacts of the scientific papers. An effort also needs to be made to develop general-interest publications (e.g., Scientific American, National Geographic), which provide an effective vehicle to translate scientific knowledge into public awareness. An active and informative web site needs to be developed so that information and images can be accessed globally. The web site should include an image library populated with high-quality photographs of coastal habitats and associated organisms which both scientists and the media can access. Within the scientific community, awareness can be raised by giving talks and posters at meetings to non-specialized audiences, emphasizing connectivity between coastal ecosystems. The literature of peer-reviewed publications and books on the various coastal habitats under threat has historically been targeted toward other researchers involved with these ecosystems. In order to reach out beyond this small group, publications aimed at non-specialized scientists need to be generated. Only by educating the broader community will the importance of the less charismatic coastal ecosystems be understood, creating a greater impetus for effective management of all vulnerable coastal ecosystems.

\section{Conclusions}

Raising the charisma of threatened coastal ecosystems, particularly necessary for seagrass meadows, requires, an increased effort by ecologists to share their insights with scientists working in other ecosystems and the public, raising awareness on their functions, their role in protecting biodiversity, and the threats to these habitats. Provided the small size of the scientific communities involved in seagrass research (e.g., typical attendance of about 150 to biannual International Seagrass Biology Symposiums), efforts to reach the public through community-level interactions appear, while effective for the individuals involved, insufficient to raise significant awareness within time scales appropriate to improve or revert the loss of coastal habitats. Scientists cannot be the sole actors in this process. Scientists can generate and convey information on the status and role of the ecosystems but need to work together with professional educators and communicators and governmental and non-governmental organizations to effectively reach the public, raising their interest on coastal ecosystems to help generate a public demand for further information and to conserve these ecosystems. Only the development of strong partnerships between coastal ecologists, networks of educators in direct contact with children, 
and mass media can expand the outreach at an appropriate scale and pace (Fig. 3, Rose and Bridgewater 2003). The conservation of threatened coastal ecosystems ultimately depends on the level of success in raising the charisma of these habitats by building public awareness on their values and the pressures responsible for their losses, a task that requires more dynamic and effective communication between scientists, science educators, the media, and coastal resource managers.

Acknowledgments This work was conducted as a part of the Global Seagrass Trajectories Working Group supported by the National Center for Ecological Analysis and Synthesis, a Center funded by NSF (Grant \#DEB-00-72909), the University of California at Santa Barbara, and the State of California, as well as a project funded by the Fundación BBVA (Spain). We thank R. Martínez and M. SánchezCamacho for help in data collection.

\section{References}

Achard, F., H.D. Eva, H.J. Stibig, P. Mayaux, J. Gallego, T. Richards, and J.P. Malingreau. 2002. Determination of deforestation rates of the world's humid tropical forests. Science 297: 999-1002.

Adam, P. 2002. Saltmarshes in a time of change. Environmental Conservation 29: 39-61.

Adger, W.N., T.P. Hughes, C. Folke, S.R. Carpenter, and J. Rockström. 2005. Social-ecological resilience to coastal disasters. Science 309: 1036-1039.

Balmford, A., and W. Bond. 2005. Trends in the state of nature and their implications for human well-being. Ecology Letters 8: 1218-1234.

Bellwood, D.R., T.P. Hughes, C. Folke, and M. Nystrom. 2004. Confronting the coral reef crisis. Nature 429: 827-833.

Cohen, J.E., C. Small, A. Mellinger, J. Gallup, and J. Sachs. 1997. Estimates of coastal populations. Science 278: 1211-1212.

Costanza, R., R. d'Arge, R. de Groot, S. Farber, M. Grasso, B. Hannon, K. Limburg, S. Naeem, R.V. O’Neill, J. Paruelo, R.G. Raskin, P. Sutton, and M. van den Belt. 1997. The value of the world's ecosystem services and natural capital. Nature 387: 253 260.

Curran, S.R., A.A. Kumar, W. Lutz, and M. Williams. 2002. Interactions between coastal and marine ecosystems and human population systems: perspectives on how consumption mediates this interaction. Ambio 31: 264-268.

Dennison, W.C., T.R. Lookingbill, T.J.B. Carruthers, J.M. Hawkey, and S.L. Carter. 2007. An eye opening approach to developing and communicating integrated environmental assessments. Frontiers in Ecology and the Environment 5: 307-314.

Duarte, C.M. 2002. The future of seagrass meadow. Environmental Conservation 29: 192-206.
Ellison, J.C., and D.R. Stoddart. 1991. Mangrove ecosystem collapse during predicted sea-level rise: Holocene analogues and implications. Journal of Coastal Research 7: 151-165.

Gardner, T.A., I.M. Cote, J.A. Gill, A. Grant, and A.R. Watkinson. 2003. Long-term region-wide declines in Caribbean corals. Science 301: 958-960.

Jackson, J.B.C., M.X. Kirby, W.H. Berger, K.A. Bjorndal, L.W. Botsford, B.J. Bourque, R.H. Bradbury, R. Cooke, J. Erlandson, J.A. Estes, T.P. Hughes, S. Kidwell, C.B. Lange, H.S. Lenihan, J.M. Pandolfi, C.H. Peterson, R.S. Steneck, M.J. Tegner, and R.R. Warneret. 2001. Historical overfishing and the recent collapse of coastal ecosystems. Science 293: 629-638.

Inglehart, R. 1995. Public support for environmental protection: Objective problems and subjective values in 43 societies. Political Science and Politics 28: 57-72.

Kathiresan, K., and N. Rajendran. 2005. Coastal mangrove forests mitigated tsunami. Estuarine Coastal Shelf Sci. 65: 601-606.

LOICZ. 2002. Report of the LOICZ synthesis and futures meeting 2002: coastal change and the anthropocene. 91The Netherlands: LOICZ international project office (IPO), Netherlands Institute for Sea Research (NIOZ), Texel.

Lotze, H.K., H.S. Lenizan, B.J. Bourque, R.H. Bradbury, R.G. Cooke, M.C. Kay, S.M. Kidwell, M.X. Kirby, C.H. Peterson, and J.B.C. Jackson. 2006. Depletion, degradation, and recovery potential of estuaries and coastal seas. Science 312: 1806-1809.

Marbà, N., C.M. Duarte, E. Díaz-Almela, J. Terrados, W. Álvarez, R. Martínez, R. Santiago, E. Gacia, and A.M. Grau. 2005. Direct evidence of imbalanced seagrass (Posidonia oceanica) shoot population dynamics along the Spanish Mediterranean. Estuaries 28: $53-62$.

National Research Council (NRC). 1990. Managing Coastal Erosion. Washington, DC, USA: National Academy Press.

Orth, R.J., T.J.B. Carruthers, W.C. Dennison, C.M. Duarte, J.W. Fourqurean, K.L. Heck, A.R. Hughes, G.A. Kendrick, W.J. Kenworthy, S. Olyarnik, F.T. Short, M. Waycott, and S.L. Williams. 2006. A global crisis for seagrass ecosystems. Bioscience 5612: 987-996.

Pernetta, J.C., and J.D. Milliman. 1995. Land-Ocean Interactions in the Coastal Zone - Implementation Plan. IGBP Global Change Report No. 33. 215. Stockholm, Sweden: International Geosphere- Biosphere Programme.

Rose, O.H., and P. Bridgewater. 2003. New approaches needed to environmental education and public awareness. Prospects 33: 263-272.

Short, F.T., and S. Wyllie-Echeverria. 1998. Natural and human-induced disturbance of seagrasses. Environmental Conservation 23: 17-27.

Thomas, J.E., T.A. Saxby, A.B. Jones, T.J.B. Carruthers, E.G. Abal, and W.C. Dennison. 2006. Communicating Science Effectively: A practical handbook for integrating visual elements. 132 . London: IWA Publishing.

Tibbetts, J. 2006. Louisiana's wetlands: A lesson in nature appreciation. Environmental Health Perspectives 114A: 40-43.

Valiela, I., J.L. Bowen, and J.K. Cork. 2001. Mangrove forests: One of the world's threatened major tropical environments. Bioscience 51: 807-815. 